\title{
BANK MERGERS PERFORMANCE AND THE DETERMINANTS OF SINGAPOREAN BANKS' EFFICIENCY An Application of Two-Stage Banking Models
}

\author{
Fadzlan Sufian \\ Muhamed-ZulkhibriAbd. Majid
}

\begin{abstract}
An event study window analysis of Data Envelopment Analysis (DEA) is employed in this study to investigate the effect of mergers and acquisitions on Singaporean domestic banking groups' efficiency. The results suggest that the mergers haveresulted in a higher post-merger mean overall efficiency of Singaporean banking groups. However, from the scale efficiency perspective, our findings do not support furtherconsolidation in the Singaporean banking sector. We find mixed evidence of the efficiency characteristics of the acquirers and targets banks. Hence, the findings do not fully support the hypothesis that a more (less) efficient bank becomes the acquirer (target). In mostcases, our results further confirm the hypothesis that the acquiring bank's mean overall efficiency improves (deteriorates) post-merger resulted from the merger with a more (less) efficient bank. Tobit regression model is employed to determine factors affecting bank performance, and the results suggest that bank profitability has a significantly positive impact on bank efficiency, whereas poor loan quality has a significantly negative influence on bank performance.
\end{abstract}

Keywords: bank merger; data envelopment analysis; Singapore; Tobit model JEL classification: G21; D24 
Gadjah Mada International Journal of Business, January - April 2007, Vol. 9, No. 1

\section{Introduction}

In recent decades, the banking sector in Singapore has been subject to globalization, deregulation, and liberalization similar to that in industrialized countries such as the EU countries and the U.S. Those changes are intertwined with merger and acquisition (M\&A) process aimed at increasing bank competitiveness and efficiency. Singaporean banking industry is a considerable component in Asian financial activities, which has not been subject to substantial research compared to that of the other countries in the developed world. As efficient banking systems contribute in an extensive way to higher economic growth in any countries, studies in this nature are very important for policy makers, industry leaders, and many others reliant on the banking sector.

The analysis of bank efficiency continues to be important from both microeconomic and macroeconomic points of view, as is documented by its long tradition in literature. From the microeconomic perspective, the issue of bank efficiency is crucial, given increasing competition and measures to further liberalize the banking system. This triggers the issue of increasing efficiency as one of the main priorities of the regulators towards the sector. From the macroeconomic perspective, the efficiency of the banking sector influences the costs of financial intermediation and the overall stability of financial market.
The motivation of this study comes firstly from the fact that despite the importance of the Singaporean banking sector to the domestic, regional, and international economies, there is only little microeconomic research conducted in this area. The present study thus addresses an important gap in the literature. Secondly, in order to appraise the effectiveness and success of the M\&A activities amongst domestic incorporated Singaporean commercial banks, it is therefore essential to conduct a formal analysis. This study attempts to provide empirical evidence for the efficiency changes in Singaporean commercial banks arising from M\&As over the past decade. Utilizing the nonparametric Data Envelopment Analysis (DEA) methodology, pure technical and scale efficiency of all domestic incorporated Singaporean commercial banks involved in M\&As is investigated. The role of merger in efficiency changes is examined by comparing the relative efficiency scores before and after the merger program. To the best of our knowledge, this method will overcome the limitations of standard method of comparing financial parameters that may not able to capture the long-term trend as well as to identify the determinants.

The paper raises four important fundamental questions: (1) Do mergers and acquisitions result in the improvement of the mean overall efficiency level of the Singaporean banking sector? (2) Does a less efficient 
Sufian \& Abd.Majid-Bank Mergers Performance and the Determinants of Singaporean Banks' Efficiency

bank become the target of acquisition? (3) Does a less (more) efficient target result in the deterioration (acceleration) in the acquirer's mean overall efficiency level post-merger? (4) What determines the relative performance of banks in Singapore?

The paper is structured as follows: the next section reviews related studies in the main literature with respect to studies on bank efficiency, Section 3 outlines the approaches to the measurement and estimation of efficiency changes, Section 4 discusses the results, and finally, Section 5 provides some concluding remarks.

\section{Literature Review}

Since 1998, when Development Bank of Singapore (DBS) acquired the Post Office Savings Bank (POSB) and
Keppel Bank merged with Tat Lee Bank, the Singaporean government has been encouraging domestic banks to consolidate to prepare them for stiffer competition from foreign banks. In fact, for the Singaporean banks to compete successfully in the new era of globalization, the government intends to eventually merge the domestic financial institutions into two "super banks".

The recent M\&A activities amongst the domestic incorporated Singaporean banks were:

- On June $12^{\text {th }}, 2001$, Singapore's third largest bank, Overseas-Chinese Banking Corporation (OCBC) announced a SGD4.8 billion bid (voluntary general offer) for Keppel Capital Holdings $(\mathrm{KCH})$, which owned Singapore's smallest bank, Keppel Tat Lee Bank.

Table 1. Characteristics of Singapore's Commercial Banks after the M \& As in 2001

\begin{tabular}{|c|c|c|c|}
\hline & DBS & UOB + OUB & OCBC + KEP \\
\hline Total Assets (S\$ billion) & 111.0 & 113.7 & 83.0 \\
\hline Total Loans (S\$ billion) & 54.2 & 61.5 & 50.4 \\
\hline Total Deposits (S\$ billion) & 92.8 & 96.6 & 71.1 \\
\hline Total Shareholders Fund (S\$ billion) & 8.4 & 13.1 & 8.3 \\
\hline Number of Branches & 107 & 93 & 74 \\
\hline Number of ATMs & 900 & 426 & 381 \\
\hline
\end{tabular}

Note: DBS is Development Bank of Singapore; UOB is United Overseas Bank; OUB is Overseas Union Bank; OCBC is Overseas-Chinese Banking Corporation; and KEP is Keppel Capital Holdings (which owns Keppel Tat Lee Bank).

Source: Banks'Annual Reports 
- On June $29^{\text {th }}, 2001$, Singapore's second largest lender, United Overseas Bank (UOB) made a competing bid for Overseas Union Bank (OUB), Singapore's fourth largest bank, after DBS Holdings Group's unsolicited bid of SGD9.4 billion for OUB. UOB's bid succeeded in August 2001, forming Singapore's largest bank in terms of assets.

Earlier evidence of cost efficiency associated with M\&As in the U.S. banking industry in the 1980s proves to be insignificant, and that the average cost curve has a relatively flat Ushape with medium sized banks being slightly more cost scale efficient than either large or small banks (Berger and Humphrey 1992; Rhodes 1993; DeYoung 1997). Average costs are usually found to be minimized somewhere in the wide range between SGD100 million and SGD10 billion of assets (Berger et al. 1987; Hunter et al. 1990; Noulas et al. 1990). However, studies in the 1990s have shown mixed results. Berger (2003) notes that it is possible that technological progress would have increased economies of scale in the production of financial services as most of the researchers used data of financial institutions in the 1980s.

Studies conducted to investigate U.S. bank mergers performance in the 1990s have arrived at different conclusions. Rhoades (1998) finds that there are modest cost efficiency gains for most M\&As involving large U.S. banks. On the other hand, Berger(1998) suggests very little improvement in cost efficiency for M\&As for both large and small banks. Nevertheless, M\&As in the 1980s and 1990s did result in the improvement in profit efficiency (Akhavein et al. 1997; Berger 1998). In addition, studies focusing on profit have been able to observe the improvement in profitability. Akhavein et al. (1997) show that M\&As help improve profitability, not by improvement in efficiency, but rather by a change in the output mix in favor of more loans and fewer securities holdings.

Berger and Humphrey (1992) and Rhoades (1993) provide evidence that if the acquiring banks are more efficient than the acquired banks, there are no efficiency gains from horizontal mergers. Someresearch has found that, in a substantial proportion of M\&As, a more efficient and larger financial institution tend to take over a smaller, less efficient one (Berger and Humphrey 1992; Pilloff and Santomero 1998). Study on European banks by Vander and Vennet (1996) also shows that larger banks with higher efficiency and profitability tend to acquire smaller banks, which are less efficient and profitable.

Earlier studies examining the effect of efficiency on bank mergers and acquisitions in the U.S. banking sector involved a large number of M\&As. However, a growing number of empirical studies have been undertaken to analyze a small number of M\&As using a nonparametric Data Envelopment Analysis (DEA) method. The DEA method has increasingly been 
Sufian \& Abd.Majid-Bank Mergers Performance and the Determinants of Singaporean Banks' Efficiency

the preferred method to investigate the impacts of mergers and acquisitions on bank efficiency, in particular if the sample size is small. Avkiran (1999) reveals that it is advisable to work with a sample size substantially larger than the product of number of inputs and number of outputs if the analysis is to discriminate effectively between efficient and inefficient decision making units (DMUs). Previous studies done to analyze a small number of $M \& A s$ include, amongst others, Avkiran (1999), Liu and Tripe (2002), and Sufian (2004).

Avkiran (1999) employed DEA and financial ratios to a small sample of 16 to 19 Australian banks during the period of 1986-1995; he studied the effects of four mergers on efficiency and the benefits to the public. He adopted the intermediation approach and two DEA models. He reports that acquiring banks are more efficient than target banks. He also finds that acquiring banks do not always maintain their pre-merger efficiency, but that, during the deregulated period, overall efficiency, employees' productivity, and return on assets (ROA) improve. There are mixed evidence from the four cases of the extent to which the benefits of efficiency gains from mergers are passed on to the public.

Liu and Tripe (2002), using a small sample of seven to 14 banks, employed accounting ratios and two DEA models to explore the efficiency of six bank mergers in New Zealand between 1989 and 1998. They find that the acquiring banks are generally larger than their targets, although they are not consistently more efficient. They also find that five of the six merged banks had efficiency gains based on the financial ratios whilst the other only achieved slight improvement in operating expenses to average total income. Predicated on the DEA analysis, they find that only some banks were more efficient than the target banks pre-merger. The results suggest that four banks had obvious efficiency gains post-merger. However, they could not decisively conclude on possible benefits of the mergers to the public.

Using a small sample size of 10 banks, Sufian (2004) investigated the impacts of the megamerger program amongst domestic incorporated Malaysian commercial banks. He finds that Malaysian banks have exhibited average overall technical efficiency level of 95.9 percent during the study period. He finds that the inefficiency amongst Malaysian banks is largely due to scale rather than pure technical, suggesting that Malaysian banks are operating at non-optimal scale of operations. He concludes that merger is particularly successful for small and medium sized banks, which have benefited the most from expansion and via economies of scale.

Although substantial studies have been performed with respect to the efficiency and productivity of financial institutions in the U.S., Europe, and other Asia-Pacific banking industries, the Singaporean banking indus- 
Gadjah Mada International Journal of Business, January - April 2007, Vol. 9, No. 1

try has not followed suite partly due to the lack of available data sources and the small sample of banks. Amongst the notable microeconomic research performed on Singaporean banks' efficiency are by Chu and Lim (1998), Rezvanian and Mehdian (2002), and Randhawa and Lim (2005).

Using the DEA with three inputs and two outputs, Chu and Lim (1998) evaluated the relative cost and profit efficiency of a panel of six Singaporean listed banks during the period 19921996. They find that during the period, the six Singaporean listed banks exhibited higher overall efficiency of 95.3 percent compared to profit efficiency of 82.6 percent. They also find that large Singaporean banks have reported higher efficiency of 99.0 percent compared to the 92.0 percent for the small banks. They also suggest that scale inefficiency dominates pure technical inefficiency during the period of study.

Rezvanian and Mehdian (2002) used parametric and nonparametric approaches to examining the production performance and cost structure of the sample of Singaporean commercial banks. The results of the parametric methodology suggest that the average cost curve of these banks is Ushaped and there are economies of scale for small and medium sized banks. Further analysis provides evidence of economies of scope for all banks regardless of their size. The nonparametric results indicate that the Singaporean banks could have reduced cost by 43 percent had they all been overall effi- cient. The sources of this cost inefficiency seem to be caused equally by allocative and technical inefficiency.

Morerecently, Randhawa andLim (2005) utilize the DEA to investigate the locally incorporated banks in Hong Kong and Singapore X-efficiency during the period of 1995-1999. They find that during the period, the seven domesticincorporated Singaporean banks exhibited average overall efficiency score of 80.4 percent under the intermediation approach and 97.2 percent under the production approach. They suggest that the large Singaporean banks have reported higher overall efficiency compared to the small banks have under the production approach, whilst the small banks have exhibited higher overall efficiency under the intermediation approach. They also suggest that pure technical inefficiency dominates scale inefficiency under both approaches during the period of study.

\section{Methodology}

\section{Data Envelopment Analysis}

The small number of banks is a serious handicap in studying the efficiency of the Singaporean banking sector. The small sample size is amongst other reasons leading us to utilize the DEA as the tool of choice for evaluating the Singaporean banks' Xefficiency. Furthermore, the DEA is less data demanding as it works fine with small sample size and does not require knowledge of proper functional 
Sufian \& Abd.Majid-Bank Mergers Performance and the Determinants of Singaporean Banks' Efficiency

form of the frontier, error, and inefficiency structures (Evanoff and Israelvich 1991, Grifell-Tatje and Lovell 1997, Bauer et al. 1998).

The term Data Envelopment Analysis (DEA) was first introduced by Charnes, Cooper, and Rhodes (1978), (hereafter CCR), to measure the efficiency of each Decision Making Units (DMUs), obtained by a maximum of a ratio of weighted outputs to weighted inputs. The CCR model presupposes that there is no significant relationship between the scale of operations and efficiency by assuming constant returns to scale (CRS), and it delivers the overall technical efficiency (OTE).

Banker et al. (1984) extended the CCR model by relaxing the CRS assumption. The resulting "BCC" model is utilized to assess the efficiency of DMUs characterized by variable returns to scale (VRS). The VRS assumption provides the measurement of pure technical efficiency (PTE), which is the measurement of technical efficiency devoid of the scale efficiency effects. If there appears to be a difference between the TE and PTE scores of a particular DMU, then it indicates the existence of scale inefficiency.

The input oriented DEA model with VRS technologies can be represented by the following linear programming problem:

$$
\begin{aligned}
& \min _{\varphi, \lambda}, \varphi \\
& \text { subject to }-\varphi y_{i},+Y \lambda, \geq 0
\end{aligned}
$$

$$
\begin{aligned}
& \mathrm{x}_{\mathrm{i}}-\mathrm{X} \lambda \geq 0 \\
& \mathrm{~N} 1{ }^{\prime} \lambda=1 \\
& \text { and } \lambda>0
\end{aligned}
$$

where $\lambda$ is an $N x 1$ intensity vector of constants and $\varphi$ is a scalar $(1 \geq \varphi \leq \infty)$. $N 1$ is an $N \times 1$ vector of ones. For $\mathrm{N}$ number of firms, $y_{i}$ and $x_{i}$ are the $M \mathrm{x} N$ and $K \times N$ output and input vectors, respectively. $Y$ comprises the data for all the $\mathrm{N}$ firms. Given a fixed level of inputs for the $i^{\text {th }}$ firm, the proportional increase in outputs to be achieved by the firm is indicated by $\varphi-1$. Note that without the convexity constraint $N 1^{\prime} \lambda=$ 1, Equation (1) becomes a DEA model with CRS technology. The convexity constraint implies that an inefficient firm is benchmarked against firms of a similar size and therefore, the projected point of that firm on the DEA frontier will be a convex combination of observed firms. In other words, each firm would be on the right of the convex production possibility frontier. If TE scores for a particular firm with or without the convexity constraint imposed are the same, then the firm is operating under CRS. If these scores are different, the firm operates under VRS technology. However, in such a case, it would be necessary to identify whether the firm or the DMU operates with IRS or DRS. To do this, an assumption of non-increasing returns to scale (NIRS) is imposed in (1) and the convexity constraint $N 1^{\prime} \lambda=1$ is substituted with $N 1^{\prime} \lambda \leq 1$. This is given as follows: 
Gadjah Mada International Journal of Business, January - April 2007, Vol. 9, No. 1

$\min _{\varphi, \lambda}, \varphi$

subject to $-\mathrm{y}_{\mathrm{i}},-\mathrm{Y} \lambda, \geq 0$

$\varphi \mathrm{x}_{\mathrm{i}}-\mathrm{X} \lambda \geq 0$

$\mathrm{N} 1^{\prime} \lambda \leq 1$

$\lambda \geq 0$

Solution to the Equation (2) reveals the nature of scale efficiency. IRS exists if TE score obtained with NIRS technology differs from the TE estimates with VRS technology. If both of these efficiency scores are equal, the corresponding firmoperates with DRS.

\section{Multivariate Tobit Regression Analysis}

It is of considerable interest to explain the determinants of the technical efficiency scores derived from the DEA model. Coelli et al. (1998) suggest several ways in which environmental variables can be accommodated in the DEA analysis. The term "environmental variables" is usually harnessed to describe factors that could influence the efficiency of a firm. In this case, such factors are not traditional inputs and are assumed to be outside the control of managers. Hence, the two-stage method used in this study involves the solution to the DEA problem at the first stage analysis, which comprises mainly the traditional outputs and inputs. At the second stage, the efficiency scores obtained from the first stage analysis are regressed on a set of bank characteristics and other environmental variables.

The standard Tobit model can be defined as follows for observation (bank) $i$ :

$$
\begin{aligned}
& \mathrm{y}_{\mathrm{i}}^{*}=\beta^{\prime} x_{\mathrm{i}}=\varepsilon_{\mathrm{i}} \\
& \mathrm{y}_{\mathrm{i}}=\mathrm{y}_{\mathrm{i}}^{*} \text { if } \mathrm{y}_{\mathrm{i}}^{*} \geq 0 \\
& \mathrm{y}_{\mathrm{i}}=0, \text { otherwise }
\end{aligned}
$$

where $\varepsilon_{i} \sim N\left(0, \sigma^{2}\right), x_{i}$ and $\beta$ are vectors of explanatory variables and unknown parameters, respectively, while $y_{i}{ }^{*}$ is a latent variable and $y_{i}$ is the DEA efficiency score. ${ }^{1}$

\section{Inputs and Outputs Definition and the Choice of Variables}

The DEA requires bank inputs and outputs whose choice is always an arbitrary issue (Berger and Humphrey 1997). In the banking theory literature, there are two salient approaches competing with each other in this regard:

\footnotetext{
${ }^{1}$ The likelihood function (L) is maximized to solve b s based on 74 observations (banks) of $y^{i}$ and $x_{i}$ is $\mathrm{L}=\prod_{\mathrm{y}_{\mathrm{i}}=0}(1-F) \prod_{\mathrm{y}_{\mathrm{i}}>0} \frac{2}{\left(2 \Pi \sigma^{2}\right)^{1 / 2}} \times e^{-\left[1 /\left(2 \sigma^{2}\right)\right]\left(\mathrm{y}^{\mathrm{i}}-\beta x_{i}\right)^{2}}$ where, $\mathrm{F}_{\mathrm{i}}=\int_{-\infty}^{\beta \mathrm{x}_{\mathrm{i}} / \sigma} \frac{1}{(2 \Pi)^{1 / 2}} e^{-\mathrm{t}^{2} / 2} d t$ The first product is over the observations for which the banks are 100 percent efficient $(y=0)$, and the second product is over the observations for which banks are inefficient $(y>0) . F_{i}$ is the distribution function of the standard normal evaluated at $\beta^{\prime} x_{i} / \sigma$.
} 
Sufian \& Abd.Majid-Bank Mergers Performance and the Determinants of Singaporean Banks' Efficiency

the production and intermediation approaches (Sealey and Lindley 1977). Under the production approach, pioneered by Benston (1965), a financial institution is defined as a producer of services for account holders, which is, it performs transactions of deposit accounts and process documents such as loans. The intermediation approach, on the other hand, assumes that financial firms act as an intermediary between savers and borrowers, and posits total loans and securities as outputs whereas deposits along with labor and physical capital are defined as inputs. For the purpose of this study, a variation of the intermediation approach or asset approach originally developed by Sealey and Lindley (1977) is adopted in defining inputs and outputs.

The aim of the choice of variables in this study is to provide a parsimonious model and to avoid the use of unnecessary variables that may reduce the degree of freedom. All variables are measured in million Singaporean Dollars (SGD million). Given the sensitivity of efficiency estimates to the specification of outputs and inputs, we estimate two alternative models. In Model 1, we follow the approach of Avkiran (1999) by including Total Deposits $(x l)$ as an input vector to produce Total Loans ( $y 1)$ and Interest Income (y3). To recognize that banks in recent years have been increasingly generating income from 'off-balance sheet' businesses and fee-based income, following Sturm and Williams (2004) amongst others, Non-Interest Income (y2), a proxy for nontraditional activities, is incorporated as the output in Model 2. Non-interest income is defined as fee income, investment income, and other income, which amongst others consist of commission, service charges and fees, guarantee fees, net profit from the sale of investment securities, and foreign exchange profit. Accordingly, in Model 2 it is assumed that Interest Income ( $y 1)$ and

Table 2. Descriptive Statistics

\begin{tabular}{|c|c|c|c|c|}
\hline Variable & Mean & Std. Dev. & Minimum & Maximum \\
\hline Total Loans $(y 1)$ & $45,348.21$ & $18,845.16$ & $12,713.56$ & $71,021.0$ \\
\hline Non-Interest Income $(y 2)$ & 727.26 & 477.50 & 73.31 & $2,153.0$ \\
\hline Interest Income $(y 3)$ & $3,201.95$ & $1,153.90$ & 944.39 & $5,298.0$ \\
\hline Total Deposits $(x l)$ & $56,598.01$ & $30,090.08$ & $12,089.23$ & $113,206.0$ \\
\hline Interest Expense $(x 2)$ & $1,674.51$ & 736.21 & 568.64 & $3,501.26$ \\
\hline Non-Interest Expense $(x 3)$ & 991.64 & 627.17 & 169.09 & $2,446.0$ \\
\hline
\end{tabular}

Note: Model $1-$ Outputs $=(y 1, y 2)$, Inputs $(x 1)$

Model $2-$ Outputs $=(y 3, y 2)$, Inputs $(x 2, x 3)$ 
Gadjah Mada International Journal of Business, January - April 2007, Vol. 9, No. 1

Table 3. Singapore Domestic Commercial Banks

\begin{tabular}{ccc}
\hline Bank & & Abbreviation Used \\
\cline { 1 - 1 } DBS Group Holdings Ltd & & DBS \\
Keppel Capital Holdings Ltd & & KEP \\
Oversea-Chinese Banking Corporation Ltd & & OCB \\
Overseas Union Bank Ltd & & OUB \\
United Overseas Bank Ltd & UOB \\
\hline
\end{tabular}

Non-Interest Income (y2) are produced from Interest Expense $(x l)$ and NonInterest Expense (x2).

\section{Data}

For the empirical analysis, all domestic incorporated Singaporean commercial banks are incorporated in the study and reported in Table 3 . In the spirit of maintaining homogeneity, only commercial banks making commercial loans and accepting deposits from the public are included in the analysis. The annual balance sheets and income statements harnessed to construct the variables for the empirical analysis are taken from published balance sheet information in annual reports of each individual bank. Three banks are omitted from this research: Bank of Singapore, Far Eastern Bank, and Industrial and Commercial Bank, which are all wholly-owned subsidiaries of the OCBC and UOB groups.

As for the potential determinants in the Tobit regressions, we use the following variables from the published annual reports of individual banks from 1998 to 2004. First, we examine the relationship between bank size and profitability. Bank size is measured by the amount of total assets and bank profitability measured by net operating income to total assets. Second, there are various bank-specific characteristics which may influence bank efficiency. We utilize three variables to explain Singaporean banks' performance: (1) capitalization, measured by the amount of share and supplementary capital divided by total assets; (2) assets quality, measured by provisions over loans; and (3) overhead cost, measured by personnel expenses over the number of employees.

\section{Assessing the Role of Mergers in Efficiency Change}

It is hypothesized that acquiring banks are more efficient than target banks (Berger and Humphrey 1992 and Rhoades 1993). For the merger cases identified in this study, the relative efficiency of the acquiring banks and the targets are monitored for a three-year period prior to the merger and that of the merged entities for three years following the merger. In the study population, two mergers that fit our criteria have taken place: 
Sufian \& Abd.Majid-Bank Mergers Performance and the Determinants of Singaporean Banks' Efficiency

Case 1: Overseas Chinese Banking Corporation acquisition of Keppel Capital Holdings on June $12^{\text {th }}, 2001$.

Case 2: United Overseas Bank acquisition of Overseas Union Bank in August 2001.

\section{Empirical Results}

In the spirit of Rhoades (1998), we develop a $[-3,3]$ event window to investigate the effect of mergers and acquisitions on the Singaporean banking groups' efficiency. The choice of the event window is motivated by Rhoades (1998), who points out that there has been unanimous agreement amongst experts that about half of any efficiency gains should be apparent after one year and all gains should be realized within three years in the wake of merger. The whole period, from 1998 to 2004 , is divided into three subperiods: 1998-2000 refers to the premerger period, 2001 is considered the merger year, and 2002-2004 represents the post-merger period, when the mergers and acquisitions are expected to have an impact on the efficiency of Singaporean banking groups. We expect to be able to capture the effect of mergers and acquisitions on the efficiency of Singaporean banks during the period. The mean overall efficiency of the targets and acquirers during all periods are compared, along with its decomposition of pure technical and scale efficiency scores. This can help shed some light on the sources of inefficiency of Singaporean banking sys- tems in general, as well as to differentiate between the targets' and acquirers' efficiency scores.

\section{Do Mergers and Acquisitions Result in the Improvement of the Mean Overall Efficiency Level of Singaporean Banking Sector?}

Model 1-Pre-merger Period. In Table 4 , the overall efficiency estimates are presented, along with their decomposition into pure technical and scale efficiency estimates for Model 1. It is apparent that during the pre-merger period, Singaporean banks exhibited an average overall efficiency score of 93.82 percent, suggesting that the Singaporean banking systems performed relatively well in its basic function - transforming deposits to loans, with relatively minimal mean input waste of 6.18 percent. The result implies that during the pre-merger period, the Singaporean banking groups could produce the same amount of outputs with only 93.82 percent of the amount of inputs used. In other words, the Singaporean banking groups could only reduce its inputs by 6.18 percent to produce the same amount of outputs produced during the pre-merger period.

Our results are in line with Chu and Lim (1998) who find that Singaporean banks showed an average overall efficiency of 95.30 percent during the period of 1992-1996, whilst Lim and Randhawa (2005) find 19.60 percent input waste amongst seven Singaporean domestic banks during 
Gadjah Mada International Journal of Business, January - April 2007, Vol. 9, No. 1

Table 4. Summary of Mean Efficiency Levels of Singapore Banks (Model 1)

\begin{tabular}{|c|c|c|c|c|c|c|c|c|c|}
\hline \multirow[t]{2}{*}{ Bank } & \multicolumn{3}{|c|}{ Pre-Merger* } & \multicolumn{3}{|c|}{ During Merger** } & \multicolumn{3}{|c|}{ Post-Merger $* * *$} \\
\hline & $\mathrm{OE}$ & PTE & SE & $\mathrm{OE}$ & PTE & SE & $\mathrm{OE}$ & PTE & SE \\
\hline KEP & 98.43 & 100.0 & 98.43 & & & & & & \\
\hline $\mathrm{OCBC}$ & 95.03 & 100.0 & 95.03 & 100.0 & 100.0 & 100.0 & 100.0 & 100.0 & 100.0 \\
\hline OUB & 99.73 & 100.0 & 99.73 & & & & & & \\
\hline UOB & 100.0 & 100.0 & 100.0 & 88.8 & 100.0 & 88.8 & 96.3 & 100.0 & 96.3 \\
\hline DBS & 75.93 & 100.0 & 75.93 & 77.2 & 100.0 & 77.2 & 100.0 & 100.0 & 100.0 \\
\hline$\overline{\text { Mean }}$ & $\overline{93.82}$ & $\overline{100.0}$ & 93.82 & $\overline{88.67}$ & $\overline{100.0}$ & $\overline{88.67}$ & $\overline{98.77}$ & $\overline{100.0}$ & $\overline{98.77}$ \\
\hline Notes & $\begin{array}{l}{ }^{*} 199 \\
\text { OE - } \\
\text { PTE - } \\
\text { SE - }\end{array}$ & Eeff & $\begin{array}{l}\text { ncy } \\
\text { al Ef } \\
\text { y }\end{array}$ & 2-2004 & & & & & \\
\hline
\end{tabular}

the period of 1995-1999. Our results are also favorably compared with Fukuyama's (1993) study on Japanese banks (14\%) and the 14-25 percent average of Indian commercial banks (Bhattacharyya et al. 1997). The decomposition of overall efficiency into pure technical and scale efficiency estimates suggests that during the premerger period, the inefficiency of the Singaporean banking sector was solely attributed to scale rather than pure technical inefficiency.

Model 1 - Post-merger Period. Despite the initial decline of the mean overall efficiency to 88.67 percent during the merger year from 93.82 percent pre-merger, it is clear from Table 4 that the mergers have resulted in the improvement of Singaporean banking groups' mean overall efficiency for Model 1 during the postmerger period. The initial decline in the mean overall efficiency during the merger year, which was solely attributed to scale inefficiency, could be due to the larger size resulting from the mergers. During the post-merger period, it is obvious from Table 4 that the Singaporean banking groups have exhibited a mean overall efficiency of 98.77 percent. In spite of exhibiting improvement in its mean overall efficiency level relative to the merger year, the only bank which was inefficient during the post-merger period, UOB, had a mean overall efficiency of 96.3 percent that was still lower than the 100.0 percent level during the premerger period. Meanwhile, DBS exhibited significant improvement in its efficiency level, operating at CRS during the post-merger period. The decomposition of the overall efficiency scores into its pure technical and scale efficiency reveals that OUB's inefficiency was attributed solely to scale during the post-merger period. 
Sufian \& Abd.Majid-Bank Mergers Performance and the Determinants of Singaporean Banks' Efficiency

Model 2-Pre-merger Period. In Table 5 , the overall efficiency estimates are presented, along with their decomposition into pure technical and scale efficiency for Model 2. It is apparent that during the pre-merger period, Singaporean banking groups exhibited a mean overall efficiency score of 97.09 percent, slightly higher compared to 93.82 percent for Model 1 . The decomposition of overall efficiency into pure technical and scale efficiency estimates suggests that during the pre-merger period, the Singaporean banks' inefficiency was largely attributed to scale $(1.43 \%)$ rather than pure technical inefficiency $(0.65 \%)$. During the period, our results indicate that all Singaporean banking groups were pure-technically efficient, with an exception of OUB, whose inefficiency was largely attributed to pure technical (3.27\%) rather than scale in- efficiency $(0.87 \%)$. It is also interesting to note that UOB was the only bank identified to be scale efficient during the pre-merger period, whilst the other Singaporean banking groups exhibited scale inefficiency in the range of 0.87 percent for OUB to 4.90 percent in the case of KEP.

Model 2 - Post-merger Period. Similar to Model 1, it is apparent from Table 5 that mergers have led to the improvement of Singaporean banking groups' mean overall efficiency for Model 2, increasing from 97.09 percent during the pre-merger period to 98.96 percent post-merger. During the post-merger period, our findings show OCBC to be the only inefficient bank due solely to scale inefficiency. It is clear from Table 5 that the largest bank in our sample, DBS, recorded significant improvement in its mean overall efficiency as the bank has operated at

Table 5. Summary of Mean Efficiency Levels of Singapore Banks (Model 2)

\begin{tabular}{|c|c|c|c|c|c|c|c|c|c|}
\hline \multirow[t]{2}{*}{ Bank } & \multicolumn{3}{|c|}{ Pre-Merger* } & \multicolumn{3}{|c|}{ During Merger** } & \multicolumn{3}{|c|}{ Post-Merger $* * *$} \\
\hline & $\mathbf{O E}$ & PTE & SE & $\mathrm{OE}$ & PTE & $\mathrm{SE}$ & OE & PTE & $\mathrm{SE}$ \\
\hline KEP & 95.1 & 100.0 & 95.1 & & & & & & \\
\hline OCBC & 98.6 & 100.0 & 98.6 & 100.0 & 100.0 & 100.0 & 96.87 & 100.0 & 96.87 \\
\hline OUB & 95.9 & 96.73 & 99.13 & & & & & & \\
\hline UOB & 100.0 & 100.0 & 100.0 & 100.0 & 100.0 & 100.0 & 100.0 & 100.0 & 100.0 \\
\hline DBS & 95.87 & 100.0 & 100.0 & 94.2 & 100.0 & 94.2 & 100.0 & 100.0 & 100.0 \\
\hline$\overline{\text { Mean }}$ & 97.09 & 99.35 & 98.57 & 98.077 & $\overline{100.0}$ & $\overline{98.07}$ & 98.96 & 100.0 & 98.96 \\
\hline
\end{tabular}

Notes: * 1998-2000; ${ }^{* *} 2001 ;{ }^{* * *} 2002-2004$

OE - Overall Efficiency

PTE - Pure Technical Efficiency

SE - Scale Efficiency 
CRS post-merger. UOB, on the other hand, has been able to continue to operate at CRS post-merger.

It is also compelling to note that despite earlier evidence suggesting that the lack of competition may result in lower technical efficiency, (see Sathye 2001, and Walker 1998), it is apparent from Table 5 that all Singaporean banking groups have reported 100 percent mean pure technical efficiency score post-merger. Walker (1998) states that the high degree of concentration in the Australian banking, dominated by four major banks, may result in the "quiet life" hypothesis to emerge. The "quiet life" hypothesis predicts a reverse causation, which is, as firms enjoy greater market power and concentration, inefficiency follows not because of noncompetitive pricing but more because of relaxed environment with no incentives to minimize costs. Hence, the findings suggest that during the period of 1998-2004, the source of inefficiency amongst Singaporean domestic incorporated banks was solely attributed to scale inefficiency.

\section{Does a Less Efficient Bank Become the Target for Acquisition?}

We now turn to the assessment of merging activities and how such a consolidation process has affected the mean overall efficiency of the involved banks. First, we analyze the pre-merger performance of the banks concerned. Theoretically, more efficient banks should acquire less efficient ones. A more efficient bank is assumed to be well organized, and has more capable management. The rationale is since there is a room for improvement regarding the performance of the less efficient bank, a takeover by the more efficient bank will lead to a transfer of the better management quality to the inefficient bank. This will in turn lead to a more efficient and better performing merged unit. In order to see whether it is indeed the case that more efficient banks acquire the inefficient ones, we calculate the difference in overall efficiency between the acquiring and the acquired banks. This efficiency difference is measured as the overall efficiency of the acquiring bank minus the mean overall efficiency of the acquired bank for the last observation period before consolidation.

For Model 1, it is clear from Table 4 that during the pre-merger period, KEP's (the target) overall efficiency level of 98.43 percent was higher compared to OCBC's (the acquirer) overall efficiency of 95.03 percent. On the contrary, it is shown that during the pre-merger period, for Model 1, UOB exhibited higher overall efficiency level of 100.0 percent compared to that of its target, OUB's overall efficiency of 99.73 percent. Therefore, our results from Model 1 reject the hypothesis that the targets are less efficient relative to the acquirers.

In contrast to Model 1 , our results for Model 2 suggest that KEP's mean overall efficiency is lower at the level of 95.1 percent than that of its acquirer, OCBC's mean overall efficiency level of 98.6 percent. Similar to Model 1, 
Sufian \& Abd.Majid-Bank Mergers Performance and the Determinants of Singaporean Banks' Efficiency

our findings indicate that during the pre-merger period, UOB's (the acquirer) mean overall efficiency of 100.0 percent is higher compared to that of its target, OUB's mean overall efficiency of 95.9 percent. Hence, our results from Model 2 support the hypothesis that the acquirers are more efficient than the targets.

\section{Does a Less (more) Efficient Target Result in the Deterioration (acceleration) in the Acquirer's Mean Overall Efficiency Level Post-merger?}

Next, we turn the discussion to the ex-post performance of the merged banking groups. The issue at hand here is whether there exists a positive (negative) relationship between the difference in the efficiency before the merger and the performance of the institution after the consolidation. In other words, we want to find out whether there has been any transfer of better management quality from the acquiring bank to the one acquired. Conversely, we would also like to inquire of whether a less efficient target would consequently result in the deterioration of the mean efficiency level of the acquirer. This is done by calculating the difference between the acquirers' mean efficiency level (overall, pure technical, and scale efficiency) during the post-merger period compared to that in the pre-merger period.

For Model 1, KEP's (the target) mean overall efficiency level of 98.43 percent was higher compared to OCBC's (the acquirer) mean overall efficiency of 95.03 percent during the pre-merger period. It is apparent from Table 6 that the merger between OCBC and KEP has resulted in the improvement of OCBC's mean overall efficiency during the merger and subsequently post-merger, when OCBC operated at CRS. In contrast, during the pre-merger period, UOB exhibited higher overall efficiency level of 100.0 percent for Model 1 than its target's, OUB's overall efficiency of 99.73 percent. These results suggest that UOB's overall efficiency deteriorated to 88.8 percent during the merger year. Although UOB's mean overall efficiency

Table 6: Summary of Mean Efficiency Levels of the Acquirers - Model 1

\begin{tabular}{|c|c|c|c|c|c|c|c|c|c|}
\hline \multirow[t]{2}{*}{ Bank } & \multicolumn{3}{|c|}{ Pre-Merger* } & \multicolumn{3}{|c|}{ During Merger** } & \multicolumn{3}{|c|}{ Post-Merger**** } \\
\hline & $\mathrm{OE}$ & PTE & SE & $\mathrm{OE}$ & PTE & SE & $\mathrm{OE}$ & PTE & SE \\
\hline $\mathrm{OCBC}$ & 95.03 & 100.0 & 95.03 & 100.0 & 100.0 & 100.0 & 100.0 & 100.0 & 100.0 \\
\hline UOB & 100.0 & 100.0 & 100.0 & 88.8 & 100.0 & 88.8 & 96.3 & 100.0 & 96.3 \\
\hline
\end{tabular}

Notes: * 1998-2000; ${ }^{* *} 2001 ;{ }^{* * *} 2002-2004$

OE - Overall Efficiency

PTE - Pure Technical Efficiency

SE - Scale Efficiency 
Gadjah Mada International Journal of Business, January - April 2007, Vol. 9, No. 1

Table 7. Summary of Mean Efficiency Levels of the Acquirers - Model 2

\begin{tabular}{|c|c|c|c|c|c|c|c|c|c|}
\hline \multirow[t]{2}{*}{ Bank } & \multicolumn{3}{|c|}{ Pre-Merger* } & \multicolumn{3}{|c|}{ During Merger** } & \multicolumn{3}{|c|}{ Post-Merger $* * *$} \\
\hline & $\mathrm{OE}$ & PTE & SE & $\mathrm{OE}$ & PTE & $\mathrm{SE}$ & $\mathrm{OE}$ & PTE & SE \\
\hline OCBC & 98.6 & 100.0 & 98.6 & 100.0 & 100.0 & 100.0 & 96.87 & 100.0 & 96.87 \\
\hline UOB & 100.0 & 100.0 & 100.0 & 100.0 & 100.0 & 100.0 & 100.0 & 100.0 & 100.0 \\
\hline te & $\begin{array}{l}\text { * } 1998- \\
\text { OE - C } \\
\text { PTE - }\end{array}$ & $\begin{array}{l}00 ;{ }^{* *} \\
\text { arall E } \\
\text { re Tec }\end{array}$ & $\begin{array}{l}01 ;{ }^{* * *} 2 \\
\text { iency } \\
\text { ical Ef }\end{array}$ & ency & & & & & \\
\hline
\end{tabular}

improved to 96.3 percent during the post-merger period, it was still lower relative to that in the pre-merger period when the bank was operating as a fully efficient bank. Based on our results for Model 1, we can conclude that a more efficient (inefficient) target results in the improvement (deterioration) of the acquirer's mean overall efficiency post-merger.

In contrast to our results from Model 1, it is apparent from Table 7 that KEP's mean overall efficiency of 95.1 percent is lower than that of its acquirer, OCBC's mean overall efficiency of 98.6 percent. It means that the merger has resulted in the deterioration of OCBC's mean overall efficiency level post-merger to 96.87 percent. For Model 2, it is clear from Table 7 that during the pre-merger period, UOB's overall efficiency of 100.0 percent was higher compared to that of its target, OUB's overall efficiency of 95.9 percent, indicating that UOB's mean overall efficiency level remained stable and that the bank was operating at CRS during the merger year, and was operating as a fully efficient bank post-merger. Hence, for Model 2, we find mixed evidence of the implication of merger on acquirers' mean overall efficiency post-merger.

\section{What Determines the Relative Performance of Banks in Singapore?}

To further investigate the determinants of efficiency performance over time, equations for the DEA Model 1 and the DEA Model 2 are estimated using the censored Tobit model by employing the DEA score for overall efficiency derived from Model 1 and Model 2. Unlike a conventional Ordinary Least Square estimation, in a case with limited dependent variables, Tobit model is known to generate consistent estimates of regression coefficients. The results of estimation are presented in Table 8. A positive coefficient implies an efficiency increase whilst a negative coefficient reflects the deterioration in efficiency. 
Sufian \& Abd.Majid-Bank Mergers Performance and the Determinants of Singaporean Banks' Efficiency

Table 8. Second Stage Tobit Regression of the Efficiency Measures and Bank Characteristics

\begin{tabular}{cccc}
\hline & & Model 1 & Model 2 \\
Bank Size & -0.037 & -0.001 \\
& $(-1.289)$ & $(-0.971)$ \\
Profitability & & $0.029^{*}$ & $0.012^{*}$ \\
& $(3.124)$ & $(4.491)$ \\
Capitalization & 0.259 & 0.087 \\
& $(1.338)$ & $(1.323)$ \\
Provisions/Loans & -0.222 & $-0.445^{*}$ \\
Overhead & $(-0.476)$ & $(-2.452)$ \\
& $3.856^{*}$ & 0.566 \\
Constant & $(3.701)$ & $(1.235)$ \\
\hline R-squared & 0.407 & $1.159^{*}$ \\
\hline
\end{tabular}

Note: t-statistics are in parenthesis.

* indicates significance at 1 percent confidence level.

Bank size has negative effect on efficiency but insignificant, indicating that larger banks have lower efficiency which could be due to complex organizational structure and moral hazard behavior. On the other hand, profitability has a significant positive relationship with bank efficiency. Banks reporting higher profitability are preferred by clients, and attract the biggest share of deposits as well as the best potential borrowers. These findings indicate that more profitable banks have higher efficiency, which corresponds with the study of Jackson and Fethi (2000).

Now we turn to the analysis of bank characteristics and their influ- ence on efficiency. As can be seen from Table 8 , capitalization variable yields a positive impact but insignificant at any conventional level in explainingbank efficiency. Theoretically, higher capitalised banks should enjoy higher level of efficiency. In conducting further investigation, we treat loans as homogenous with respect to risk. We are forced to make such an assumption as we could not correct our model for risk without a thorough investigation of the causes of bad loans (Berger and DeYoung 1997). If a bank has a poor quality loan portfolio, this should entail additional costs associated with monitoring and enforcement of the loan repayment. The signifi- 
cantly negative coefficient of the provisions/loans variable gives support to the above prediction.

At first glance, the effect of overhead expenses on Singaporean banks' efficiency seems counterintuitive where higher overhead costs seem to pay off. Theoretically, consolidation should reduce the amount of backoffice personnels; however, the reduction could be offset by an increase in the front office personnels, implying better customer services. Furthermore, as suggested by Sathye (2001), more professional management may require higher remunerations; accordingly, a significantly positive relationship with efficiency measure is natural. The result is also consistent with Claessens et al. (2001), showing that the overstaffing of domestic banks in middle-income countries always leads to the deterioration in bank efficiency worse than that in high income countries.

\section{Conclusions}

Applying a nonparametric frontier approach, the Data Envelopment Analysis (DEA), this paper attempts to investigate the effect of mergers and acquisitions on Singaporean banking groups' efficiency. The sample period is divided into three sub-periods: premerger, during merger, and postmerger periods, to compare the difference in Singaporean banking groups' mean efficiency level during all periods. Given the sensitivity of efficiency estimates to the specification of inputs and outputs used, we have adopted a variant of the intermediation approach to two models.

For Model 1, our findings suggest that the Singaporean banking groups have exhibited a commendable overall efficiency level of 93.82 percent, indicating minimal input waste of 6.18 percent. We find that during the merger year, the Singaporean banking groups' overall efficiency level deteriorated slightly to 88.67 percent, which was solely due to scale inefficiency. Nevertheless, during the post merger period, the Singaporean banking groups exhibited higher mean overall efficiency level compared to that in the pre-merger period. Similar to the premerger period, our results suggest that scale inefficiency dominated pure technical inefficiency in the Singaporean banking sector post-merger. We also find from Model 2 that the Singaporean banking groups were relatively efficient in their intermediation role, exhibiting relatively minimal input waste of 2.91 percent during the pre-merger period. In contrast to the results from Model 1, our results from Model 2 indicate that the Singaporean banking groups' mean overall efficiency level was higher during the merger year and further improved during the postmerger period.

Although mergers have resulted in a more efficient banking system, as it appears from our results for Model 1 and Model 2, size has become the biggest source influencing the inefficiency of the Singaporean banking sector. Henceforth, from the scale efficiency perspective, our results do not 
Sufian \& Abd.Majid-Bank Mergers Performance and the Determinants of Singaporean Banks' Efficiency

support for further consolidation in the Singaporean banking sector to create two 'super banks'. Predicated on the findings from Model 1 and Model 2, further increase in size would only result in a smaller increase of outputs for every proportionate increase in inputs, resulting from the fact that the Singaporean banking groups have been operating at constant returns to scale and declining returns to scale during the post-merger period.

We find mixed evidence of the characteristics of the acquirers' and targets' efficiency. Since our results from the merger between KEP and OCBC reveal mixed findings, the hypothesis of a less efficient bank becoming a merger target is not fully substantiated. On the other hand, in the case of OUB and UOB merger, our results suggest that in both models, the acquirer exhibited higher mean overall efficiency level compared to that of the target during the pre-merger period.

Our results frombothmodels show that the merger between KEP and OCBC supports the hypothesis that the acquiring bank's mean overall efficiency improves (deteriorates) post- merger resulting from the merger with a more (less) efficient bank. On the other hand, in the case of OUB-UOB merger, whilst our results from Model 1 support the hypothesis that the acquirer's mean overall efficiency deteriorates post-merger resulting from the merger with a less efficient target, we do not find the same evidence for Model 2.

The explanation of the efficiency scores using Tobit regressions offers beneficial economic insights. We interpret the significance of profitability as an indication of the ability to attract the biggest share of deposits as well as the best potential borrowers. The significance of the level of loans quality portfolio proxied by bad loans provision should entail additional costs associated with monitoring and enforcement of loans repayment, hence negatively related to efficiency. Not surprisingly, on account of the high complexity of banking environment in Singapore, overhead costs tend to contribute positively to bank efficiency which could be due to highly skilled personnels with high remuneration packages.

\section{References}

Akhavein, J. D., A. N. Berger, and D. B. Humphrey. 1997. The effects of megamergers on efficiency and prices: Evidence from a bank profit function. Review of Industrial Organization 12 (1): 95-139.

Avkiran, N. K. 1999. The evidence on efficiency gains: The role of mergers and the benefits to the public. Journal of Banking and Finance 23: 991-1013. 
Banker, R. D., A. Charnes, and W. W. Cooper. 1984. Some models for estimating technical and scale inefficiencies in data envelopment analysis. Management Science 30: 1078-1092.

Bauer, P. W., A. N. Berger, G. D. Ferrier, and D. B. Humphrey. 1998. Consistency conditions for regulatory analysis of financial institutions: A comparison of frontier efficiency methods. Journal of Economics and Business 50: 85-114.

Benston, G. J. 1965. Branch banking and economies of scale. Journal of Finance 20 (2): 312-331.

Berger, A. N. 1998. The efficiency effects of bank mergers and acquisitions: A preliminary look at the 1990s data. In Y. Amihud and G. Miller (edt.), Bank Mergers and Acquisitions. Boston: Kluwer Academic Publishers.

Berger, A. N. 2003. The integration of the financial services industry: Where are the efficiencies? North American Actuarial Journal 4 (3): 25-52.

Berger, A. N., and R. DeYoung, R. 1997. Problem loans and cost efficiency in commercial banks. Journal of Banking and Finance 21: 849 - 870.

Berger, A. N., and D. B. Humphrey. 1992. Megamergers in banking and the use of cost efficiency as an antitrust defense. Antitrust Bulletin 37 (3): 541-600.

Berger, A. N., and D. B. Humphrey. 1997. Efficiency of financial institutions: International survey and directions for future research. European Journal of Operational Research 98: 175-212.

Berger, A. N., G. A. Hanweck, and D. B. Humphrey. 1987. Competitive viability in banking: Scale scope and product mix economies. Journal of Monetary Economics 20 (3): 501-520.

Bhattacharya, A., C. A. K. Lovell, and P. Sahay. 1997. The impact of liberalization on the productive efficiency of Indian Commercial Banks. European Journal of Operational Research 98: 332-345.

Charnes, A., W. W. Cooper, and E. Rhodes. 1978. Measuring the efficiency of decision making units. European Journal of Operational Research 2: 429-444.

Chu, S. F., and G. H. Lim. 1998. Share performance and profit efficiency of banks in an oligopolistic market: Evidence from Singapore. Journal of Multinational Financial Management 8: 155-168.

Claessens, S., A. Demirguç-Kunt, and H. Huizinga. 2001. How does foreign entry affect the domestic banking market? Journal of Banking and Finance 25 (5): 891-911.

Coelli, T., D. S. Prasada-Rao, and G. E. Battese. 1998. An Introduction to Efficiency and Productivity Analysis. Boston: Kluwer Academic Publishers.

DeYoung, R. 1997. A diagnostic test for distribution free estimator: An example using U.S. Commercial Bank Data. European Journal of Operational Research 98 (2): 243-249.

Evanoff. D. D., and P. R. Israelvich. 1991. Productive efficiency in banking. Economic Perspectives. Chicago: Federal Reserve Bank of Chicago: 11-32.

Fukuyama, H. 1993. Technical and scale efficiency of Japanese commercial banks: A non-parametric approach. Applied Economics 25: 1101-1012. 


\section{Sufian \& Abd.Majid-Bank Mergers Performance and the Determinants of Singaporean Banks’ Efficiency}

Grifell-Tatje, E., and C. A. K. Lovell. 1997. The sources of productivity change in Spanish Banking. European Journal of Operational Research: 98, 364-380.

Hunter, W. C., S. G. Timme, and W. K. Yang. 1990. An examination of cost subaddivity and multiproduct production in large U.S. Banks. Journal of Money, Credit and Banking 22 (4): 504-525.

Jackson, F. M., and M. D. Fethi. 2000. Evaluating the technical efficiency of Turkish Commercial Banks: An application of DEA and tobit analysis. Departmental Working Paper. Leicester: University of Leicester.

Liu, B., and D. Tripe. 2002. New Zealand bank mergers and efficiency gains. Journal of Asia Pacific Business 4 (4): 61-81.

Noulas, A.G., S. C. Ray, and S. M. Miller. 1990. Returns to scale and input substitution for large U.S. Banks. Journal of Money, Credit and Banking 22 (1): 94-108.

Pilloff, S. J., and A. M. Santomero. 1998. The value effects of bank mergers and acquisitions. In Y. Amihud, and G. Miller (eds.), Bank Mergers and Acquisitions. Boston: Kluwer Academic Publishers.

Randhawa, D.S., and G. H. Lim. 2005. Competition, liberalization and efficiency: Evidence from a two stage banking models on banks in Hong Kong and Singapore. Managerial Finance 31: 52-77.

Rezvanian, R., and S. Mehdian. 2002. An examination of cost structure and production performance of commercial banks in Singapore. Journal of Banking and Finance 26: 79-98.

Rhoades, S. A. 1993. Efficiency effects of horizontal (in-market) bank mergers. Journal of Banking and Finance 17 (2-3): 411-422.

Rhoades, S. A. 1998. The efficiency effects of bank mergers: An overview of case studies of nine mergers. Journal of Banking and Finance 22: 273-291.

Sathye, M. 2001. X-Efficiency in Australian banking: An empirical investigation. Journal of Banking and Finance 25: 613-630.

Sealey, C., and J. T. Lindley. 1977. Inputs, outputs and a theory of production and cost at depository financial institutions. Journal of Finance 32: 1251-1266.

Sturm, J., and B. Williams. 2004. Foreign bank entry, deregulation and bank efficiency: Lessons from the Australian experience. Journal of Banking and Finance 28 (7): $1775-1799$

Sufian, F. 2004. The efficiency effects of bank mergers and acquisitions in a developing economy: Evidence from Malaysia. International Journal of Applied Econometrics and Quantitative Studies 1 (4): 53-74.

Vander V. R. 1996. The effects of mergers and acquisitions on the efficiency and profitability of EC credit institutions. Journal of Banking and Finance 20: 15311558.

Walker, G. 1998. Economies of sale in Australian Banks 1978-1990. Australian Economic Papers 37: 71-87. 